\title{
Cesarean Scar Ectopic Pregnancy
}

\section{Sunil V. Jagtap ${ }^{1}$, Nitin Kshirsagar ${ }^{2}$, Ramnik Singh $^{3}$, Shreya Tuli ${ }^{4}$, Parneet Kaur ${ }^{5}$, Swati S. Jagtap 6}

${ }^{1}$ Professor, Department of Pathology, Krishna Institute of Medical Sciences Deemed University, Karad, India.

${ }^{2}$ Professor, Department of Obstetrics \& Gynecology, Krishna Institute of Medical Sciences Deemed University, Karad, India.

${ }^{3,4,5}$ Assistant Lecturer, Department of Pathology, Krishna Institute of Medical Sciences Deemed University, Karad, India.

${ }^{6}$ Associate Professor, Department of Physiology, Krishna Institute of Medical Sciences Deemed University, Karad, India.

Corresponding Author: Sunil Vitthalrao Jagtap

\begin{abstract}
Caesarean Scar Ectopic Pregnancy (CSEP) is one of the rarest forms of ectopic pregnancy. We present a 30 year female presented with 8 weeks of amenorrhea. Her obstetric history was G3P2D2. Her B HCG levels were $>10,000 \mathrm{IU} / \mathrm{L}$. She had history of previous 2 lower uterine segment Caesarean section. She was referred to our hospital in stage of severe hypovolemic shock related to vaginal bleeding. USG findings were suggestive of death of fetus of about 6 weeks 5 days. Gestational -sac at lower uterine segment Caesarean section scar level. Radiological diagnosis was? Scar pregnancy. On histopathology diagnosed as Caesarean scar ectopic pregnancy with area of rupture in anterolateral wall of lower uterine segment and upper cervix. The endometrium was unremarkable. We are presenting this case for its rarity, clinical radiological and histopathological findings.
\end{abstract}

Keywords- Scar ectopic pregnancy, Uterine rupture, Gestation, Caesarean section.

\section{INTRODUCTION}

Cesarean scar pregnancy is the rarest form of ectopic pregnancy. The word "ectopic" means "out of place". Its incidence has been rising and estimated to occur in $0.05-0.4 \%$ ( 1 in 1800 to 1 in 2500 ) of all pregnancies. It is related to increasing number of cesarean deliveries. [1,2,3] Cesarean scar pregnancy rate accounts for $6 \%$ of ectopic pregnancies among women with a prior cesarean delivery. It occurs after any myometrial trauma.

The overall increased cesarean deliveries worldwide, has resulted in high rates of repeat cesarean deliveries, surgically-related infections, bowel and bladder injury, transfusions, hysterectomy, abnormal placentation, cesarean scar pregnancy and worsening maternal morbidity. ${ }^{[4]}$

\section{CASE REPORT}

A 30 year female presented with 8 weeks of amenorrhea. She was taking treatment at local rural medical hospital for severe pain in lower abdomen associated with heavy vaginal bleeding. She had history of previous 2 lower (uterine) segment Caesarean section. Her obstetric history was G3P2D2. She was referred to our hospital in stage of severe hypovolemic shock related to vaginal bleeding. Her B HCG levels were $>10,000$ IU/L. USG findings suggestive of death of fetus of about 6 weeks 5 days. Gestational -sac at lower (uterine) segment Caesarean section scar level. Radiological diagnosis was ? scar pregnancy, with acute sub chorionic hemorrhage separating sac posteriorly. The cervical os was partially opened. 
We received specimen of uterus with cervix with scar ectopic pregnancy. On gross examination a specimen of uterus and cervix measured $10.9 \times 5.5 \times 3.5 \mathrm{~cm}$ and weighing $120 \mathrm{gm}$. External surface of lower anterior and right lateral surface of uterus and upper cervix showed irregular scar with destruction of wall measuring 1.8 $\mathrm{x} 1.5 \times 1.2 \mathrm{~cm}$. On cut section showed large areas of hemorrhage, blood clot and distorted ectopic gestational sac (Figure1,2). The defect was covered with hemorrhage and blood clot. On cut section endometrial canal measures $5.5 \mathrm{~cm}$ in length and uterine cavity was empty. Average endometrial thickness was $0.4 \mathrm{~mm}$. Average myometrial thickness was $1 \mathrm{~cm}$. Cervical canal was empty

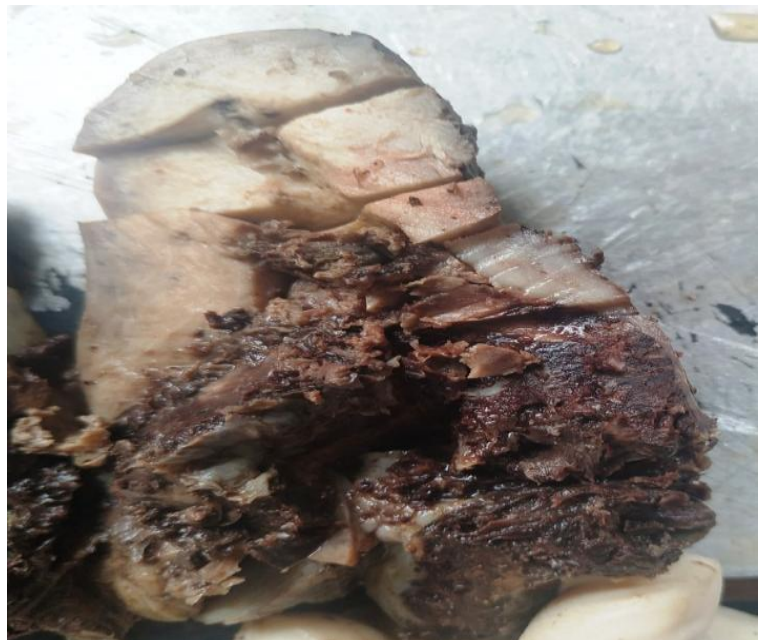

Figure-1. Lower anterior and right lateral surface of uterus and upper cervix showed irregular scar with destruction of wall and hemorrhage.

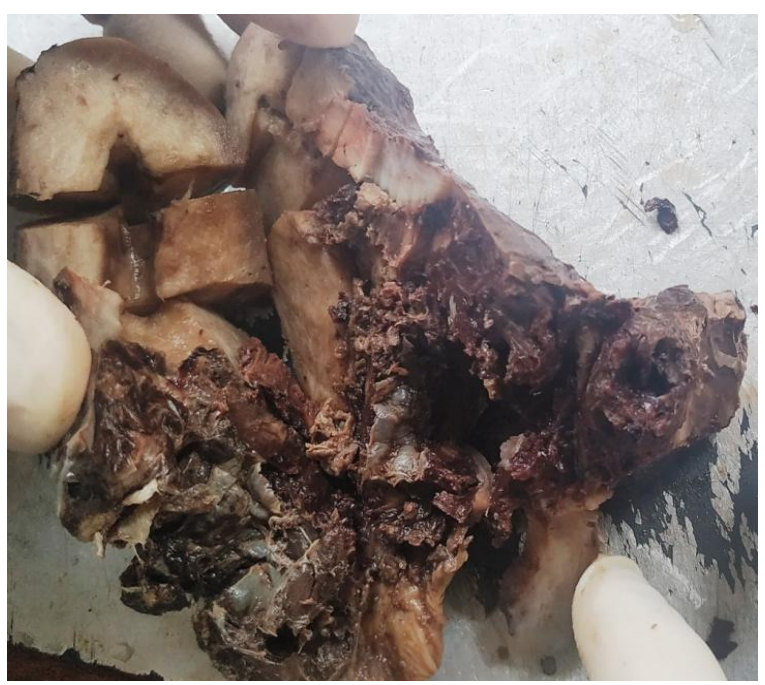

Figure-2. Gross Caesarean scar ectopic pregnancy.
On histopathology diagnosed as Caesarean scar ectopic pregnancy with area of rupture in anterolateral wall of lower uterine segment and upper cervix (Figure$3,4)$.The endometrium was unremarkable.

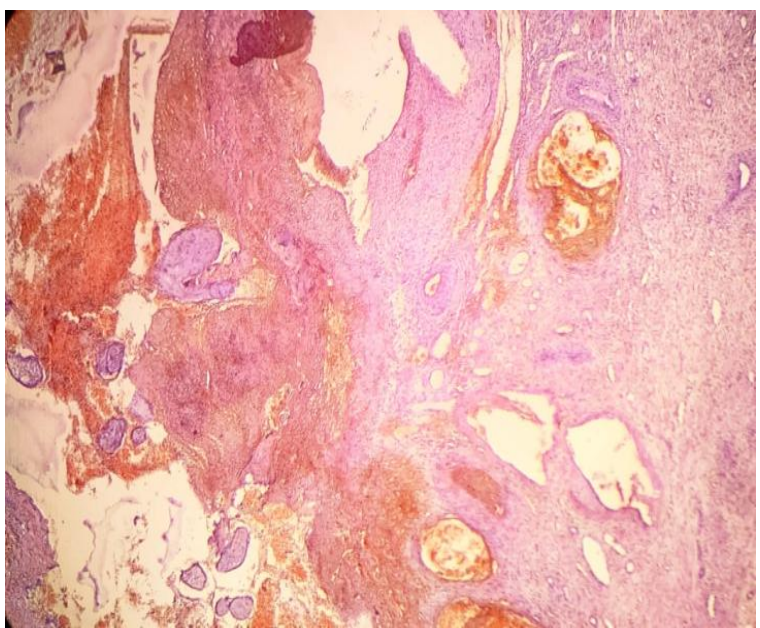

Figure-3. Gestation implanted in a caesarean section scar and surrounded by the myometrium and the fibrous tissue of the $\operatorname{scar}(\mathbf{H} \& E$ Stain,x100)

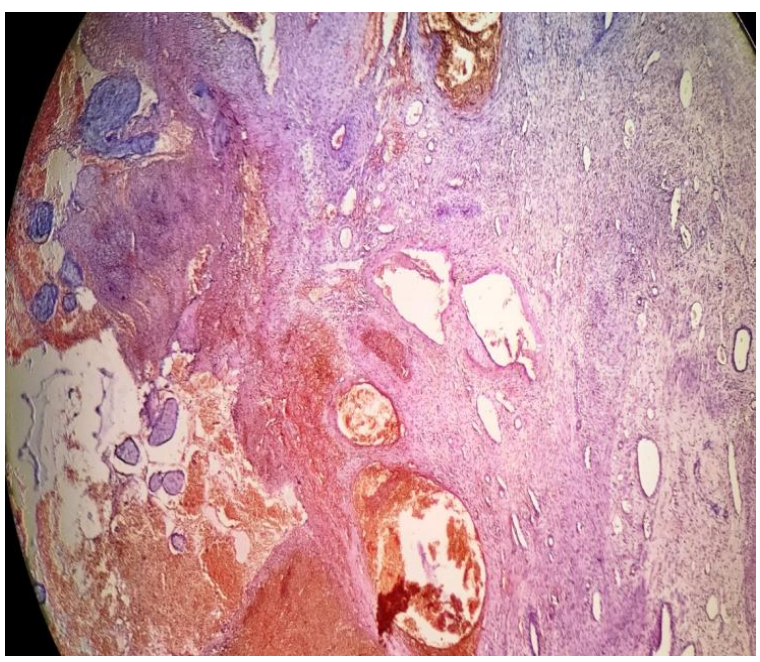

Figure-4. Villi and sac in a caesarean section scar and surrounded by the myometrium with areas of hemorrhages. (H \&E Stain,x100)

\section{DISCUSSION}

Caesarean Scar Ectopic Pregnancy (CSEP) is one of the rarest forms of ectopic pregnancy. It is characterised by a gestation implanted in a caesarean section scar and surrounded by the myometrium and the fibrous tissue of the scar. The gestational sac is not in the uterine cavity and chorionic villi implants on scar. The gestational age at diagnosis ranged from 5 to 12.4 weeks.

The types of CSEP are a) Type I: Endogenic type- it is characterised by 
implantation on the CS with progression towards the direction of the endometrial cavity, it may continue to develop and progress to the second and third trimesters. b) Type II: Exogenic type -it is a deep implantation in the CS defect growing mainly towards the abdominal cavity. It is associated with early uterine rupture or invasion into the urinary bladder. ${ }^{[5]}$

The mechanism for implantation in this condition remains uncertain. It is believed to be migration of the embryo through either the wedge defect in the lower uterine segment or a microscopic fistula within the scar which develops due to poor healing of the previous trauma caused by caesarean section, dilatation and curettage, hysterotomy, myomectomy, abnormal placentation and manual removal of placenta. ${ }^{[6]}$

In scar ectopic pregnancies the clinical presentation ranges from asymptomatic, pain in lower abdomen to heavy vaginal bleeding, uterine rupture, haemoperitoneum and hypovolemic shock, life-threatening haemorrhage, disseminated intravascular coagulation and even a death. [6]

In our case patient referred from rural hospitalvery late, in stage of heavy bleeding and with shock.

The diagnosis of scar ectopic pregnancy depends on symptoms, clinical manifestation, history of previous scar. In addition to it estimation of serum $\beta$ hCG level and radio imaging like transvaginal sonography. Diagnosis of scar ectopic pregnancy is relatively easy in early pregnancy. The transvaginal sonography diagnosis includes (a) an empty uterine cavity and cervical canal, (b) an gestational sac located at the anterior wall of the isthmic portion, separated from endometrial cavity or fallopian tube in previous caesarean scar, (c) a gestational sac embedded within the myometrium and the fibrous tissue of caesarean section scar at the lower uterine segment with an absence of defect in the myometrium between the bladder and the sac and (d) a high-velocity low-impedance vascular flow surrounds the gestational sac. ${ }^{[7]}$

However, it is difficult to differentiate scar ectopic pregnancy from anterior cervical ectopic pregnancy, inevitable abortion or a cervicoisthmic pregnancy. Hence, high-resolution and color ultrasound scanning is essential for differential diagnosis.

On microscopic examination the myometrium is usually thins out to merge with the thin and fibrous scar of previous caesarean section. The placental attachment in the lower segment may lack both decidua basalis and myometrium, merely consisting of some connective tissue

The undiagnosed scar ectopic pregnancy can present with heavy bleeding, haemoperitoneum and shock. Diagnosis of scar ectopic pregnancy is relatively easy in early pregnancy. The differential diagnosis includes spontaneous abortion, cervicoisthmic ectopic pregnancy, gestational trophoblastic tumor and placenta accrete. ${ }^{[7,8]}$ In spontaneous abortion, the gestation sac should be seen in the cervical canal on TVS, and on colour flow Doppler, the sac should appear avascular, indicating that the sac has been detached from its implantation site.

In cervico pregnancy, there would be a layer of healthy myometrium visible between the bladder and the gestation sac on USG and bleeding as the presenting symptom is much heavier. To determine whether a Cesarean scar ectopic pregnancies has occurred, ultrasound in a sagittal position can be used to indicate a clear uterine cavity and an empty cervical canal.

Distinguishing between a Cesarean scar ectopic pregnancies, a cervical isthmic pregnancy, or a spontaneous abortion that is still in progress can be difficult.

The treatment approach depends on various factors like gestational age, haemodynamic stability, availability of endoscopic expertise, further fertility and feasibility of serial follow-up by serology and imaging. It has been noted that the trophoblastic tissue is unreachable to 
curette, and repeated attempt can cause uterine perforation leading to severe haemorrhage.

Conservative medical management includes systemic methotrexate, local embryocides or combination of both. While the surgical management to the patients who are haemodynamically unstable or failed with medical therapies includes hysteroscopy, laparoscopy, laparotomy. ${ }^{[9]}$

To prevent and control profuse bleeding, various haemostatic majors in form of intrauterine balloon tamponade by Foley's catheter, local injection of vasopressin, Shirodkar's suture, prior selective uterine artery embolization and bilateral uterine artery ligation are advised. ${ }^{[10]}$

The immediate complications of cesarean scar pregnancy are uterine rupture and severe bleeding in this situation there is need for hysterectomy. The same was observed in our case. The study by Shukla et al showed that the incidence of ectopic pregnancies is on rise. In order to reduce the morbidity and mortality due to ectopic pregnancies, there is need for early diagnosis. $^{[11]}$

\section{CONCLUSION}

Incidence of Caesarean scar ectopic pregnancy is increasing because of a rising number of caesarean sections. The CSEP is a life threatening condition and requires prompt diagnosis on clinical, radio imaging and proper management to reduce associated morbidity.

\section{Acknowledgement: None Conflict of Interest: None Source of Funding: None}

\section{REFERENCES}

1. Jayaram PM, Okunoye GO, Konje J. Caesarean scar ectopic pregnancy: Diagnostic challenges and management options. Obstetrics and Gynecology. 2017; 19:13-20.

2. M. A. Rotas, S. Haberman, and M. Levgur, "Cesarean scar ectopic pregnancies: etiology, diagnosis, and management," Obstetrics and Gynecology. 2006 ; 107,6, 1373-1381.

3. Odgers HL, Taylor RA, Balendran J, Benness C, Ludlow J. Rupture of a caesarean scar ectopic pregnancy: A case report. Case Reports in Women's Health. 2019;22:e0120.

4. Boerma T, Ronsmans C, Melesse DY, et al. Global epidemiology of use of and disparities in caesarean sections. Lancet. 2018;392:1341-1348.

5. Gonzalez N, Tulandi T. Cesarean scar pregnancy: A systematic review. Journal of Minimally Invasive Gynecology. 2017; 24:731-738

6. Y Vial, P. Petignat, and P. Hohlfeld, "Pregnancy in a cesarean scar," Ultrasound in Obstetrics and Gynecology. 2000; 16, 6, 592-593.

7. Timor-Tritsch IE, Monteogrido A, Santos R, Tsymbal T, Pineda G, Arslan AA. The diagnosis, treatment and follow up of cesarean scar pregnancy. Am $\mathrm{J}$ of Obstet Gynecol. 2012;207(1):44.

8. Jagtap SV, Aher V, Gadhiya S, Jagtap SS. Gestational Trophoblastic Disease Clinicopathological Study at Tertiary Care Hospital. J Clin Diagn Res. 2017;11(8):EC27-EC30.

9. M. Kanat-Pektas, S. Bodur, O. Dundar, and V. L. Bakır, "Systematic review: what is the best first-line approach for cesarean section ectopic pregnancy?" Taiwanese Journal of Obstetrics and Gynecology.2016;55,2:263269.

10. X.Y. Yang, H. Yu, K.M. Li, Y.X. Chu, A. Z heng.Uterine artery embolization combined with local methotrexate for treatment of caesarean scar pregnancy.BJOG -an International Journal of Obstetrics and Gynaecology.2010, 117(8): 990-996.

11. Shukla DB, Jagtap SV, Kale PP, Thakkar HN. Study of ectopic pregnancy in a tertiary care centre. Int J Reprod Contracept Obstet Gynecol 2017;6:975-9.

How to cite this article: Jagtap SV, Kshirsagar $\mathrm{N}$, Singh $\mathrm{R}$ et.al. Cesarean scar ectopic pregnancy. Int J Health Sci Res. 2021; 11(5): 358-361. DOI: https://doi.org/10.52403/ijhsr. 20210556 